\title{
LA REINA MARÍA DE CASTILLA Y EL PATRONAZGO ESPIRITUAL EN ARAGÓN BAJO LAS DIRECTRICES DE LA OBSERVANCIA
}

\author{
QUEEN MARIA OF CASTILE AND THE SPIRITUAL PATRONAGE IN ARAGON \\ UNDER THE GUIDELINES OF OBSERVANCE
}

\author{
Carmen ROSARIO TORREJÓN \\ Universitat de València \\ carme.rosario@gmail.com
}

\begin{abstract}
Resumen: El patrocinio y soporte económico hacia las casas de religiosos fue uno de los métodos mediante el cual las reinas podían demostrar su poder o reforzar su linaje. La creación o reforma de conventos, monasterios u hospitales no cumplió una función meramente piadosa por parte de su promotor, sino que además jugó un papel fundamental con respecto al control político de sus reinos. Para María de Castilla (1401-1458), reina de Aragón, el respaldo hacia ciertos cenobios fue acompañado de la difusión de la Reforma Observante. En ese sentido, el artículo estudia a la reina como benefactora del convento de Santa María de Jesús y el Hospital de Gracia, en Zaragoza, y la iglesia de Magallón, además de destacar su aptitud y manejo en la resolución de los problemas de convivencia de ciertos monasterios aragoneses, a través de las noticias aparecidas básica-
\end{abstract}

\begin{abstract}
Patronage and financial support for religious houses was one of the methods by which queens could demonstrate their power or reinforce their lineage. The creation or reform of convents, monasteries or hospitals did not merely fulfil a pious function on the part of their promoter, but also played a fundamental role with regard to the political control of their kingdoms. For María of Castile (1401-1458), Queen of Aragon, support for certain monasteries was accompanied by the spread of the Observant Reformation. This article studies this monarch as benefactress of the convent of Santa María de Jesús and the hospital of Gracia in Zaragoza, and the church of Magallón as well as highlighting her aptitude and management in resolving the problems of coexistence of certain Aragonese monasteries, through the news that
\end{abstract}


mente en los registros de la Real Cancillería de la reina custodiados en el ARV y ACA.

Palabras clave: María de Castilla, Reino de Aragón, Reforma franciscana observante, Convento de Santa María de Jesús de Zaragoza, Hospital de Gracia de Zaragoza, Iglesia de Magallón. basically appeared in the records of the Queen's Royal Chancery kept in the Archives of the Kingdom of Valencia and the Crown of Aragon.

Keywords: María of Castile, Kingdom of Aragon, Observant Franciscan Reform, Convent of Santa María de Jesús de Zaragoza, Hospital de Gracia of Zaragoza, Church of Magallón.

\section{María de Castilla y las influencias de otras reinas medievales}

En este artículo se van a presentar parte de los resultados de nuestra tesis doctoral dedicada a la promoción artística y cultural de la reina María de Castilla en el ámbito de la Corona de Aragón. ${ }^{1}$ Concretamente se abordarán únicamente las actuaciones concernientes al Reino de Aragón. El aporte documental que se presenta — base esencial de este estudio- procede fundamentalmente del Archivo de la Corona de Aragón y del Archivo del Reino de Valencia, y ofrece nueva información relativa a la promoción y reforma de monasterios o iglesias, poniendo en especial valor el papel jugado por la reina en la resolución de conflictos dentro de los ámbitos monacales. ${ }^{2}$

1 Carmen Rosario Torrejón (2020), La promoció artística de la reina Maria de Castella. Art $i$ cultura a la Corona d'Aragó al segle XV. Tesis doctoral inédita. València, Universitat de València.

2 Entre los trabajos dedicados al papel promotor de la reina caben destacar las investigaciones de María del Carmen García-Herrero (2013-2014), «De belleza y piedad. Promociones de María de Castilla, reina de Aragón (1416-1458)», Lambard. Estudis d'Art medieval, 25: 37-62; _ (2012), «Aragón y el Monasterio de la Trinidad de Valencia: la renuncia a financiar el proyecto de la reina María.» En Mundos medievales: espacios, sociedades y poder: homenaje al profesor José Ángel García de Cortázar y Aguirre. Universidad de Cantabria: 1365-1378; _ (2017), «Reginalidad y fundaciones monásticas en las Coronas de Castilla y Aragón», Edad Media. Revista de Historia, 18: 16-48. También son de interés las siguientes investigaciones: María Teresa Vicens Soler (2009), «Aproximació al món artístic de la reina Maria de Castella.» En Maria Rosa Terés Tomàs (coord.), Capítula facta et firmata, inquietuds artístiques en el Quatre-cents. Barcelona, Cossetània: 193-262; Jacobo Vidal Franquet (2014), «La cámara real de María de Castilla. Sus joyas y otras delicias suntuarias», Anales de Historia del Arte, 24: 593-610. O el trabajo de Juan Vicente García-Marsilla (2007), «La demanda y el gusto artístico con la Valencia de los siglos XIV al XVI.» En Ximo Company, Vicente Pons, Joan Aliaga (eds.), Libro de estudios. Exposició La Llum de les Imatges, Lux Mundi. València, Generalitat Valenciana: 375-407. Así mismo, son de ineludible referencia las obras de Francisca Hernández-León de Sánchez (1959), Doña María de Castilla, esposa de Alfonso V el magnánimo. València, Universitat de València; María Narbona Cárceles (2013), «De casa de la senyora Reyna. L'entourage de Marie de Castille, épouse 
María de Castilla, primogénita de Enrique III el Doliente y de Catalina de Lancaster, casó con su primo Alfonso, más conocido como el Magnánimo, y se convirtió en reina de Aragón entre los años 1416 y 1458. Aparte de su carrera política con el ejercicio de la lugartenencia después de que el rey Alfonso $\mathrm{V}$ partiese a las campañas expansionistas italianas, tuvo un especial interés en el fomento y la fundación de conventos, monasterios y obras pías (García Herrero, 2017: 46). Este acercamiento hacia la fundación y el patrocinio se inicia de forma conjunta con rey antes de la lugartenencia, pero después de la partida del monarca de los reinos peninsulares las promociones de la reina toman su propio rumbo, exceptuando alguna actuación conjunta con el rey que parece tener, más bien, un carácter institucional que efectivo. La reina María seguía, de esta manera, la estela iniciada por otras reinas que la precedieron, así como también de miembros importantes de su familia como lo fue su madre, Catalina de Lancaster, o su cuñada, María de Trastámara.

El amparo por parte de las reinas y nobles hacia la fundación de edificios religiosos y obras pías fue una tónica general durante la Edad Media. Bien fuera para demostrar su devoción religiosa, para residir en ellos o erigir allí sus sepulcros, era una de las formas mediante la cual las reinas, en este caso, podían destacar como figura política. A partir de ahí, la elección de una determinada orden monástica $\mathrm{u}$ otra era fruto de una decisión personal e ideológico-religiosa.

En el caso de la Corona de Aragón había una tendencia a impulsar instituciones franciscanas, especialmente de clarisas. Entre las monarcas que desarrollaron un programa destinado a beneficiar fundaciones de esta orden destacan, por un lado, Blanca de Anjou (1280-1310), que hizo donaciones al convento de Vilafranca del Penedés, o la reina Elionor de Sicilia (1325-1375), que fundó el convento femenino de Santa Clara de Teruel y favoreció el de Santa Clara de Calatayud, además de apoyar otras órdenes como por ejemplo la congregación cisterciense de Sijena. Aunque, sin duda, si hubo una reina que hizo de sus patrocinios una muestra de su fuerza política y un logro personal destinado a recordar a su propia persona y linaje, esa fue Elisenda de Montcada. Su obra más importante fue la fundación del monasterio de clarisas

d'Alphonse le Magnanime (1416-1458).» En Alexandra Beauchamp, Les entourages princiers à la fin du Moyen Âge. Une approche quantitative. Madrid, Casa de Velázquez: 151-167; y Theresa Earenfight (2010), The King's other body: María of Castile and the Crown of Aragon. Philadelphia, University of Pennsylvania Press. 
de Santa María de Pedralbes de Barcelona (García Herrero y Muñoz, 2017: 31). A diferencia de las anteriores, que se limitaron a favorecer monasterios y conventos, y que fueron enterradas en los panteones familiares de Santes Creus o Poblet, respectivamente, Elisenda decidió vivir en el monasterio que había fundado y además lo convirtió en su lugar póstumo de descanso, su panteón particular. ${ }^{3}$ Estas actuaciones fortalecían el peso y poder de decisión de las reinas, puesto que evidenciaban un interés por hacer obras únicas y propias. Conviene, por tanto, tenerlo en cuenta cuando estudiemos las líneas de actuación de María de Castilla.

Además del apoyo a los mendicantes, otras órdenes como los jerónimos, cartujos o carmelitas continuaron ocupando un espacio dentro de los programas fundacionales de muchas soberanas. Como apunta Diana Pelaz, gracias a la predilección por el culto a la Virgen, por parte de los jerónimos y los cartujos, que a su vez era tan venerada por muchas monarcas (entre ellas la reina María), estas órdenes supieron mantenerse en una posición privilegiada a la hora de beneficiarse del favor real (Pelaz, 2018: 408). Una de las reinas que más acercamiento tuvo hacia los jerónimos fue Violante de Bar (1365-1431), y eso se materializó en la construcción del monasterio de la Vall d'Hebrón de Barcelona, continuado después por María de Castilla. La reina María heredó de ésta un gusto por las novedades artísticas y los objetos suntuosos procedentes de Borgoña y Francia que se pueden apreciar en la compra de telas, vestidos, joyas y pequeñas esculturas descritas en el inventario que se realizó tras su muerte (Toledo, 1961).

Otro aspecto a destacar, de estas reinas medievales, era su acercamiento hacia las nuevas corrientes de misticismo que desde el siglo XII reivindicaban una nueva lectura de los textos religiosos diferente a la teología preestablecida por parte de la Iglesia, donde la experiencia de la santidad femenina se alcanzaba mediante la purificación del espíritu. Se trataba de generar un acercamiento mucho más intimista y personal hacia Dios. Estas ideas estaban muy en la línea de la Devotio moderna y el desarrollo de la Reforma Observante. Leonor de Aragón y Castilla, hija ilegítima de Enrique de Villena i sobrina de la reina María de Castilla, que entró en el convento de la Santísima Trinidad de Valencia en 1445 con el nombre de Isabel de Villena, también fue una mon-

3 Además de fundar y erigir dicho cenobio la reina se preocupó por que sus escudos decorasen tanto el convento como la iglesia. El hecho de hacer un sepulcro doble, que miraba hacia el claustro y también hacia la iglesia, donde podría ser contemplada por los fieles, denota un interés por querer ser recordada. 
ja en conexión con estas nuevas corrientes místicas. El hecho, sin duda, de haberse criado en la corte de la reina la acercó seguramente a estas nuevas ideas (Graña, 2018: 116).

Por su parte, en la Corona de Castilla, también proliferó el acercamiento hacia las órdenes mendicantes y especialmente hacia las clarisas entre las principales mujeres de la realeza. Tal fue el caso de María de Molina, que fue protectora del convento de Santa Clara de Guadalajara y del de Santa Clara y Santo Espíritu de Toro, aunque prefiriese ser enterrada en el monasterio cisterciense de las Huelgas Reales de Burgos. Por otro lado, la reina Catalina de Lancaster, madre de María de Castilla, participó de la fundación de diversos conventos, durante el siglo XIV, como por ejemplo el de Santa María la Real de Nieva, donde se retiró de viuda, y el de San Pedro de Mayorga, pertenecientes ambos a la orden de predicadores. La misma estela siguieron Beatriz de Portugal en Santo Espíritu de Toro, o Leonor de Alburquerque (madre de Alfonso el Magnánimo) que cambió la antigua advocación premostratense de Santa María de los Huertos de Medina del Campo por la de Santa María la Real, poblándola con dominicas (Graña, 2017: 75-100). El fervor por la orden de predicadores expresado por la madre de la reina (pero también por la reina María de Trastámara) se hizo notar en algunas fundaciones de María de Castilla, muy especialmente en la creación de una Capilla Real en el convento de Santo Domingo de Valencia, lugar que pretendía ser su panteón real junto con Alfonso V, pero que definitivamente no se materializó. Este interés por parte de la reina hacia el favorecimiento de los dominicos se puede explicar desde el punto de vista de dar continuidad a los gustos e intereses de su estirpe familiar (Pelaz, 2018: 409).

Otro hecho muy remarcable de Catalina de Lancaster, y que influiría posteriormente en María de Castilla, fue la decoración de Santa María de Nieva, no solamente con sus escudos sino también con los emblemas. Este hecho, sin duda, tenía la misión de reforzar su papel como reina. La reina María incorporó también sus propios escudos y emblemas en el sepulcro que mandó esculpir para sí en el monasterio de la Santísima Trinidad de Valencia, cenobio que fundó y que, al igual que Elisenda de Montcada, lo enunciaba como: nostre monestir (Narbona, 2014-2015).

En definitiva, se puede decir que la reina María buscó, como ya hicieran sus antecesoras Elisenda de Montcada, María de Luna o Catalina de Lancaster, hacer valer su condición de reina, no solamente con la fundación o patrocinio de edificios religiosos, sino desarrollando una obra en memoria de su 
propia persona a través de la erección de un convento para su retiro y enterrándose en él, practicando la caridad y el pietismo, siguiendo el ejemplo de la Observancia y, al mismo tiempo, invocando su linaje familiar, como ya hiciera su madre y otros miembros de los Trastámara.

\section{María de Castilla y la Reforma Observante}

Profundicemos ahora en el aspecto que más caracterizó a la política de fundaciones y subvenciones de monasterios y conventos de la reina María de Castilla: el seguimiento de aquella reforma llamada Observancia, que se inició en el siglo XIV y a la que hemos hecho alusión anteriormente, emprendida primero por su predecesora, la reina María de Luna (1358-1406), en el monasterio franciscano de Santo Espíritu del Monte en Sagunto (Valencia) junto con el religioso Francesc Eiximenis. Si bien es cierto que en un inicio las promociones que hizo María de Castilla fueron junto con el rey, el distanciamiento de éste y la consiguiente lugartenencia de la reina posibilitaron que emprendiera un programa personal y en solitario. Las fundaciones más importantes de la reina estuvieron dirigidas a promover y construir conventos mendicantes, especialmente para los franciscanos y dominicos. No obstante, tampoco olvidó la renovación de hospitales e iglesias.

Entre los objetivos de dicha reforma estuvo el retorno a las raíces del franciscanismo: la austeridad y el espíritu de pobreza que predicó San Francisco de Asís. En definitiva, una vuelta al rigor de la regla que se había ido diluyendo conforme las diversas ordenes empezaron a acumular riquezas y posesiones al mismo tiempo que sucumbieron a diversos excesos y transgresiones morales. ¿Pero únicamente le preocupaba a la reina este aspecto espiritual? Aparte de los intereses religiosos, la misión de la monarca iba más allá. Así pues, como veremos después de analizar algunos problemas a los que tuvo que hacer frente en muchas de estas casas de religiosos, su misión respondía a establecer una «red» de conventos u monasterios afines a la reforma observante con la cual la reina podía establecer un control de los religiosos. En definitiva, un control político por todos sus dominios para así afianzar el peso de los Trastámara en la Corona de Aragón y al mismo tiempo hacer valer su autoridad reginal con independencia de su marido.

La reina María, aunque manifestaba un empeño particular por divulgar esta reforma no estuvo sola, pues contó con la ayuda y colaboración de un francis- 
cano llamado Mateo de Agrigento. Este religioso, del que no se conoce un origen cierto — se cree que nació en 1376 o 1377 en la ciudad italiana de Agrigento, al sur de Sicilia_- fue seguidor de las prédicas de Bernardino de Siena, otro fraile franciscano que difundió la palabra de Dios por la península itálica. El beato de Agrigento empezó a extender sus prédicas junto a fray Bernardino, y están documentados ambos en Lombardía y Brescia entre 1418 y 1422; unos años después se les uniría en esta labor otro religioso llamado Giovanni da Capestrano.

El programa de Bernardino de Siena consistió en predicar la devoción por el sagrado Nombre de Jesús, que difundía de forma visual a través del anagrama IHS. Dicho religioso se dedicó a orar públicamente, como ya hiciese en su día el dominico valenciano Vicente Ferrer. Esta labor fue imitada por Mateo, quien, incluso, recomendaba a la población portar estampas e imágenes con las letras IHS, a modo de elemento de protección divina ( $\mathrm{Ru}-$ bió, 1964: 30). Así pues, mientras fray Mateo estuvo en Mesina, potenció el culto hacia el Sagrado Nombre de Jesús junto con el de María, madre de Dios, y se encargó de que dicho anagrama estuviese representado en las paredes del convento que él mismo fundó en 1425 y que estuvo dedicado a Santa María de Jesús. Años después, su labor lo llevó a promocionar otros cenobios como, por ejemplo, el de Santa María de Jesús en Palermo (Rotolo, 2006: 109-117).

\section{La relación de María de Castilla y Mateo de Agrigento}

Fue tal la fama que alcanzó este religioso que llegó a oídos de la corte aragonesa, con quien estableció una relación que se gestó en la primera mitad del siglo XV. El rey Alfonso El Magnánimo fue precisamente benefactor de los conventos que el fraile fundó en Sicilia, concretamente el de San Nicolás de Agrigento, que recibió del monarca 400 florines de oro. ${ }^{4}$ Es posible que los intereses de Alfonso V fueran más allá de la simple devoción, pues el rey siguió muy de cerca la política de la isla de Nápoles y es muy probable que, tal y como señala Filippo Rotolo, quisiera ganarse la estima y protección de los Observantes para favorecer su establecimiento en tierras italianas. No obstan-

4 Archivo de la Corona de Aragón (ACA), Real Cancillería (RC) 2.677 (1428), f. 73 v. Cf. Ludovico Maria Mariani (OFM) (1993), Beato Matteo frate minore vescovo di Agrigento. Palermo, Kefagrafica lo Giudice. 
te, lo cierto es que tanto el rey como la reina María estuvieron siempre al lado de estas nuevas corrientes derivadas de la espiritualidad propugnada y predicada por Bernardino de Siena y el propio Mateo de Agrigento (Rotolo, 2006: 136-137).

La reina empezó a interesarse no solamente por los sermones de Mateo sino también por sus milagros y quiso conocerlo en persona. La primera noticia que tenemos de Mateo de Agrigento en la Península Ibérica en relación con la reina María es de 1426, y es bien conocida a través de una carta que la monarca envió al fraile solicitando poder escuchar sus sermones. Así pues, al año siguiente, fray Mateo aparece documentado en Valencia predicando durante la Cuaresma (Rubió, 1990: 49). A partir de entonces comenzó una colaboración destinada a la fundación de nuevos cenobios y a la difusión del Nombre de Jesús, representando iconográficamente el anagrama Bernardino por los nuevos conventos que se procedieron a fundar y reformar. ${ }^{5}$

En sus primeros años como reina, María de Castilla conoció de primera mano los preceptos de la Observancia: en Barcelona fundó, junto con el monarca, el convento de Santa María de Jesús, aprovechando que Mateo de Agrigento estaba en la ciudad Condal. Un año más tarde, en 1428, la reina María y el rey Alfonso fundaron conjuntamente el convento de Santa María de Jesús de Valencia (Riera, 2011: 5-6). ${ }^{6}$ Sin duda, la tarea llevada a cabo por el fraile de Agrigento en los territorios ibéricos fue una continuación de sus obras iniciadas en Italia. La visita a Barcelona y a Valencia fue muy reveladora para la monarca y resulta muy probable que el religioso le explicase sus pretensiones relativas a la difusión de la Observancia por el territorio peninsular. Este hecho debió ser aprovechado por María de Castilla para hacer que el franciscano se quedara en la Península más tiempo del que tenía previsto, pues su intención era volver a Sicilia para continuar con sus responsabilidades. Para ello, la

5 El deseo de Mateo de Agrigento de llevar el anagrama siempre consigo era tal que él mismo lo pregonaba por doquier e imprimía sus propias estampas. Incluso la reina María señala que las hacía «com emprenta que tiene». Tal fue la divulgación de este anagrama que lo encontraremos como elemento común incluso en la cerámica de mesa de la época.

6 En realidad, fue la reina quien envió a fray Mateo a Barcelona para que diese asistencia espiritual y reconfortase a la población después de sufrir los efectos de unos devastadores terremotos: E per aquesta rao lo señor Rey e nos vehent la desolació d'aquesta ciutat per consolació de vosaltres, e del poble d'aquella havem lo pregant e induyt de anar aquí creent la sua anada esser molt devota. ACA, RC 3.179 (1427), f. 46. Según el Cronicó de la Seu de Girona, dentro de los templos de la diócesis murieron más de mil personas; en Barcelona cayó el rosetón de Santa María del Mar; también afectó a ciertos muros del Palacio Mayor, así como a un número considerable de casas; en el castillo de la Suda de Tortosa también se documentó la caída de piedras, entre muchas otras desgracias. 
reina se encargó de enviar a Italia a otro religioso que cumpliera con las obligaciones de fray Mateo. ${ }^{7}$

La tarea de buscar sustitutos para el fraile de Agrigento fue ardua. A la reina le llevó algún tiempo lograr que la estancia del religioso fuese más o menos prolongada, y así tener la posibilidad de instaurar los siete Conventos Observantes que había previsto para todos los territorios peninsulares de la Corona. ${ }^{8}$ Para ello envió a Bernat Escoriola, superior del convento de Xelva (València), al cenobio de Morvedre (Sagunto, València) a fin de que sustituyese a Jaume Domingo, a quien la reina decidió mandar al Capítulo General de la Orden y ocupar el lugar de fray Mateo. ${ }^{9}$

Mateo de Agrigento tuvo, por tanto, la protección de la reina al mismo tiempo que éste influyó en ella para incorporar el Nombre de Jesús en los edificios que María de Castilla promovía o reformaba. Es más, el beato lo fusionó con el nombre de la Virgen María y por ello muchas fundaciones de la Observancia adoptaron el nombre de Santa María de Jesús como se hizo en el caso del convento de Barcelona o de Valencia (Giménez, 1908: 71-81). A partir de entonces, la reina proyectó y edificó nuevos conventos en Catalunya y también en Aragón bajo esta advocación.

\section{Fundación y ampliación del Convento de Santa María de Jesús de Zaragoza}

Como capital de la provincia franciscana de la Observancia la reina no descuidó establecer nuevos monasterios y conventos en el reino de Aragón, y

7 En Miquel Roda, lo senyor rey e nos conaixem de la perfecció e santedat de frare Matheu. Per ço que romangudes de part de ça per consolació e instrucción [...] havem tractat e fer que en loch se'n baja a capítol general on ell devia anar en les parts de Ytalia frare Jacme Domingo, persona molt honesta e virtuosa, la qual de present ab aquesta letra se va aquí per cullir e anar al dit capítol per que us pregam affectuosament per contemplació vostra així en a ver bona fusta com en altra manam en totes coses a son bon desempatxament... ACA, RC 3.170 (1427), f. 63 r. Cf. Jordi Rubió i Balaguer (1964), La cultura catalana del Renaixement a la decadència. Barcelona, Ed. 62.

8 Item que haia en memoria los fets de frare Matheu, ço és a ver potestat del pare sant que puxa conferir VII Monastirs de la Regla de sant Francesc de Observancia de aquella en qualsevol parts del senyor rey no es pase licencia o consentiment algu dels diecesans. E que los frares dels Monastirs hedificats e hedificadors puxen elegir vicari que presidesca als dits monastirs. ACA RC 3.170 (1427), f. 97 v. Véase también Rubió i Balaguer (1964): 36-37.

9 En la carta dice: La Reyna. Lo señor Rey e nos per certes causes [...] havem fet tornar e de fet ses ordonat e deliberat que frare Jacme Domingo guardià del Monestir dels frares menors de Morvedre baja en las partidas de Italia al capitol general de lur orde e que frare Bernat Escoriola guardià del Monestir de Xelva sia guardià del dit Monestir de Morvedre. ACA, RC 3.170, f. 48 r. 


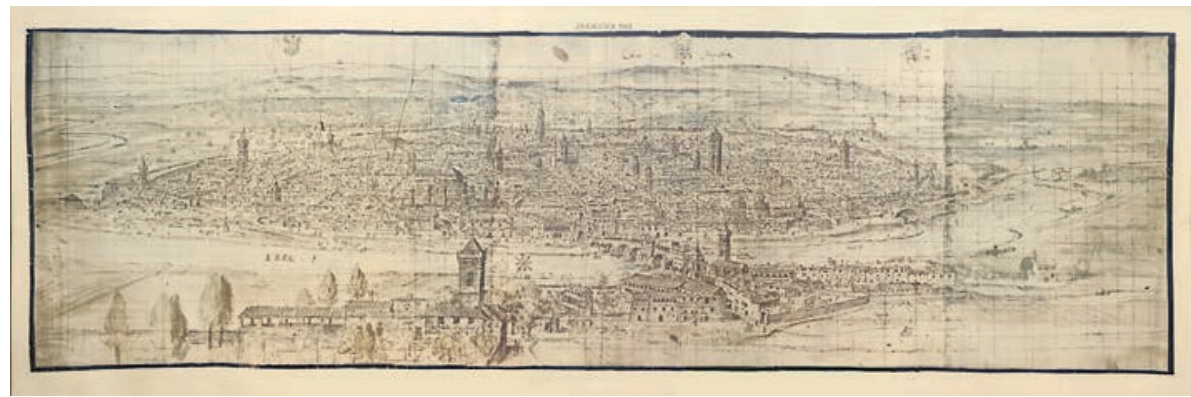

Fig. 1. Vista de Zaragoza de Athonie van den Wijngaerde (detalle del Monasterio de Santa María de Jesús en primer plano), 1563. Fuente: www.wikipedia.es.

ese fue, concretamente, el de Santa María de Jesús. Según las noticias del cronista de la Corona de Aragón, José Hebrera, sabemos que la fundación zaragozana constituyó una de las obras más importantes que la reina y fray Mateo de Agrigento emprendieron. Respecto a la información sobre este complejo, otros cronistas como Mantuano o fray Diego Murillo (Zaragoza, 15551616), que fue predicador y poeta, en su obra Fundación Milagrosa de la capilla Angélica y Apostólica de la Madre de Dios del Pilar y Excelencias de la Imperial Ciudad de Çaragoça hizo, concretamente, una historia de la ciudad y de los monumentos de Zaragoza desde la época romana hasta el siglo XVI referenciando este convento. ${ }^{11}$

Los primeros franciscanos que se establecieron en Zaragoza se instalaron muy cerca de la muralla y de la puerta Cinegia, en el centro de la ciudad (Falcón, 2011). Al igual que en otras ciudades y villas, éstos fueron acogidos en casas de particulares; posteriormente consiguieron erigir sus primeros conventos. En pleno siglo XV se documentó la presencia de los primeros Observantes en la ciudad del Ebro. De acuerdo con los relatos de Diego Murillo, se ubicaron en la margen izquierda del río, en el arrabal de Altabás. El convento,

10 Archivo:Vista de Zaragoza (1563).JPG - Wikipedia, la enciclopedia libre [consultado el 25/01/2021].

11 José Antonio Hebrera y Esmir (1705), Chronica seráfica de la santa provincia de Aragón de la Regular Observancia de nuestro padre San Francisco. Vol. II, Zaragoza, Diego de Larube impresor: 61; Fr. Diego Murillo (1616), Fundación Milagrosa de la capilla Angélica y Apostólica de la Madre de Dios del Pilar y excelencias de la Imperial ciudad de Çaragoça. Barcelona, Sebastián Mateuad, mencionado en Pilar Lop Otín (2010), «El convento de Nuestra Señora de Jesús de Zaragoza: presentación de un plano inédito del 1880», Artigrama, 25: 491-506. 
según este autor y las noticias que aportaron otros cronistas, se comenzó a edificar en 1447 y fue observante desde su fundación. ${ }^{12}$ No obstante, a partir de la información de la Real Cancillería de la reina María, sabemos que ella colaboró en la erección de la iglesia y convento. Para ello invirtió la no menospreciable suma de 200 florines, además de poner la primera piedra en 1452, lo que nos da una fecha concreta del inicio de su construcción. ${ }^{13}$ Según la documentación localizada, la reina tuvo gran disposición para que fuese un importante convento, con todo lo necesario, aunque para ello hubiera que comprar terrenos anexos pertenecientes a una capilla en propiedad de un religioso llamado Sasa. Transcribimos dicha carta a continuación:

\section{La Reyna}

Benerable Pare en Cristo amado nuestro bien creyemos no ignorays como por ampliación de la devoción del poble cristiano desa Ciudad se ha deliberado fazer un monasterio de la santa Observancia de los ffrayres de sant Francisco fuera esta ciudat cerca sant Lázaro e ya la obra de aquell es bien avanzada. E por dar spacios necesarios e convenientes a les coses necesarias por el dicho Monasterio assi por sglesia e como convent, e otras es muy necessario un campo contiguo al dicho Monasterio al qual campo se dize seyer de una capiela que es de un capellán clamado Sasa sustituida por don Andreu de la Naja en la Iglesia de santa Maria de la Naja faze de trahudo cada un anyo L sueldos pagadores en la fiesta de Santa María de Agosto. E por quanto el dicho benefficiado es quento delexar el dicho campo dando el otro tal e meyor. Resta y solamente vuestra autoridat e descreto, por que vos rogamos e encargamos que en les dichas cosas por amor e contemplación nuestra querades dar e poner vuestro derecho e autoridat por tanto benefficio e necessidat vuestra que es obra meritòria nos vos lo haremos a

12 Véase la Bula de Eugenio IV, mencionada en Chiara Mancinelli (2017), «La Observancia franciscana en la provincia de Aragón (1380 ca.-1517): Aproximación a su estudio», Archivo Ibero-Americano, 77, 284: 53-67, o Fr. Diego Murillo (1616), Fundación Milagrosa de la capilla Angélica y Apostólica de la Madre de Dios del Pilar y excelencias de la Imperial ciudad de Çaragoça. Barcelona, Sebastián Mateuad: 370 .

13 La Reyna. Reverend pare en Crist e amat nostre. No ignorats quant merexen per lur bona e santa vida èsser favorits e mantenguts los frares del Monastir de la Observança dels menors novament edifficat prop aqueixa Ciutat. E per la devoció que aquell havem hi donam CC florins e volem cus pregam molt affectuosament en la sglésia que.s deu començar posets per nos una pedra e encara altra per vos affi participets en lo mèrit car no pocha reputació e favor darets al Monastir lo qual haiats en bona recomendació car la qüestió lo és moguda se mostra èsser maliciosa com se tropia lo privilegi apostolical per lo qual lo Senyor Rey ha pogut e pot haver atorgada la licència segons d'aquestes coses vos plaurà pus larch lo amat nostre Eximeno Gordo ciutadà de la dita Ciutat nos plènament informat al qual darets fes creença axí com a nostra pròpia persona ab aquella obra e effecte dins de vos confiam e speram. E sia Reverend pare en Crist e amat nostre vostra special guarda la santa Trinitat dada en Barchinona a $X$ dies de Març del any Mil CCCCLII. Dada al aquebisbe de Saragossa. ARV, RC 8 (1452), f. 24 r. 
Servicio e complacencia dada en Çaragoça a 8 dies de febrero del anyo 1455. La Reyna. ${ }^{14}$

Es evidente que debió ser un gran complejo, y todavía lo era cuando lo describió Murillo al señalar que:

El edifico deste Monasterio es muy grande, y tiene hermosísimas vistas, porque está muy cerca del Rio y a la vista de la Ciudad, y muy cercano de Huertas por todas partes; tiene muy buenos claustros, y tres dormitorios muy largos y anchirosos, de los buenos ay en la religión; el uno dellos hizo la Ciudad, y los otros dos el Excellentisimo Señor Don Hernando de Aragón Arçobispo de Çaragoça. ${ }^{15}$

Además, según las vistas que realizó Anthoine van den Wijngaerde (Fig. 1.) cuando estuvo en Zaragoza en 1563, se puede apreciar que este monasterio tenía un claustro a doble altura; la iglesia, que poseía una torre cuadrangular de estilo mudéjar, estaba dividida en cuatro tramos y rematada por una cabecera plana. Hecho que también se puede apreciar en planta, según un plano localizado por Pilar Lop Otín (Fig. 2.; Lop, 2010: 493).

En el siglo XVI el complejo se completó con diversas estancias. Entre ellas, las que se realizaron a expensas de Francisco Herbás, camarero de la Seo, a quien se le atribuye la mencionada torre de la iglesia de estilo mudéjar, las dependencias posteriores a la cabecera del templo o la capilla mayor. Más tarde, Francisco Ariño, ciudadano de Zaragoza, patrocinó la biblioteca y la sala capitular. Sea como fuere, no hay duda de que la reina quiso proyectar uno de los cenobios franciscanos Observantes más grandes en la principal ciudad del Reino de Aragón.

\section{Otras fundaciones de la reina María en Zaragoza}

Tal y como hemos apuntado, no fueron únicamente los franciscanos quienes ocuparon un papel especial en la vida y la espiritualidad de la reina María. Como tampoco lo fueron solamente los conventos o monasterios. Aunque en número no se contabilizan muchas nuevas fundaciones o reformas en iglesias y hospitales por parte de esta monarca, lo cierto es que se registraron algunas

14 ARV, RC 16 (1455), ff. 108 v y 109 r.

15 Fray Diego Murillo (1616), Fundación Milagrosa de la capilla Angélica y Apostólica de la Madre de Dios del Pilar y excelencias de la Imperial ciudad de Çaragoça. Barcelona, Sebastián Mateuad: 370. 


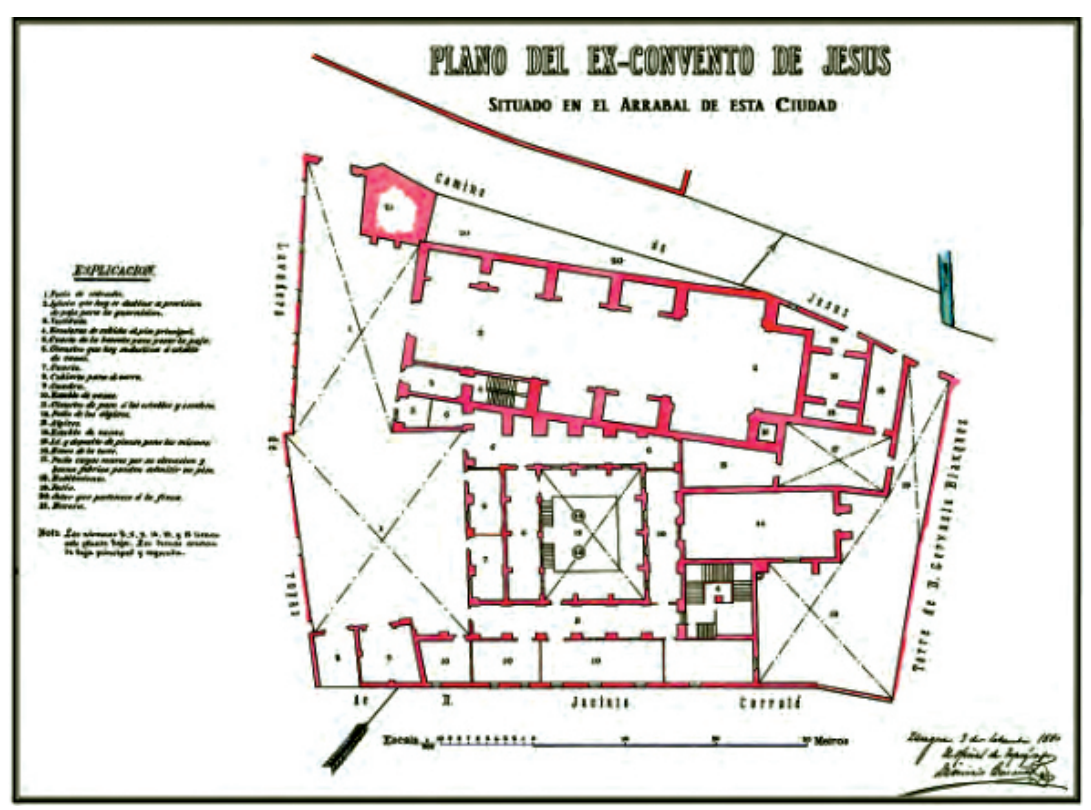

Fig. 2. Plano del Monasterio de Santa María de Jesús. Fuente: Archivo General Militar de Segovia [AGMS], Sección 3ª, División 3a, legajo 789, f. 1 r-2v. ${ }^{16}$

actuaciones que demuestran sus preocupaciones caritativas. Una de estas intervenciones se llevó a cabo en una de las iglesias de Magallón, cerca de Borja. Magallón, villa de realengo, junto con la ciudad de Borja, pasaron a formar parte de la dote de la reina Violante de Bar y, con posterioridad, fueron compradas por el rey Alfonso el Magnánimo en 1443 por 11.000 libras barcelonesas (Pano, Hernando y Sancho, 2002. Vol. I: 16). En esta población, situada en la margen izquierda del río Huecha y al norte del Moncayo, se erigieron en el siglo XIV la Iglesia de San Lorenzo Mártir (sobre el antiguo castillo de la vi1la) y la iglesia de Santa María de la Huerta. Según la documentación de la Real Cancillería, la reina quiso colaborar en la construcción de una iglesia (aunque no especificaba cual), llevada a cabo por los jurados y el Justicia de Borja; para ello hizo un envío de piedra a través del maestro de obra, que se encontraba construyendo al mismo tiempo un aljibe en el castillo de Borja.

16 Este plano está publicado en: Pilar Lop Otín (2010), «El convento de Nuestra Señora de Jesús de Zaragoza: presentación de un plano inédito del 1880», Artigrama, 25: 491-506. 


\begin{abstract}
La Reina
Baile, segon somos informada a instancia de Enyego de Lobera vecino de Tarazona e de Maestre Martin de la Ram habitant en nuestra villa de Magallón es estada aprensa de manifiesto por la cort del justícia de Aragón toda la piedra que es estada apareiada para la obra de la Iglesia de la dicha villa de Magallón, por la cual razón ressa et ha ressado la dicha obra de la dicha Iglesia. E como aquella dicha obra Mahir de la Rabita judío que era, segon la obligación en que es continuar, e sin haber la dicha piedra como dicho es no sea possible, e atendido que tenemos voluntat la dicha obra se continue, e en la dicha manifestación no sea fecha lesion vos rogamos e encargamos e mandamos que al maestro que faze la obra del aljub de nuestro Castillo de Borja, e a un otro que sia en semblant negocio. ${ }^{17}$
\end{abstract}

Con el tiempo, la reina volvió a enviar otra carta para interesarse por la obra y la conclusión de la iglesia en $1459 .{ }^{18}$ Desgraciadamente la monarca ya no vio el templo terminado, pues murió en 1458. Parece ser que el hecho de que se retrasase tanto aquella obra fue porque las piedras que se destinaron para la edificación fueron robadas, y hasta que no se recuperaron no se logró concluir. ${ }^{19}$ Desgraciadamente, sin la referencia directa, es muy difícil saber si la iglesia a la que se refiere el texto era la de San Lorenzo o la Iglesia de Santa María de la Huerta. Aun así, por la mención que hace de la piedra como material indispensable para concluir la iglesia podríamos aventurar que se refiriese a la primera, es decir, a la de San Lorenzo. Este edificio, que se inició en el siglo XIV, aunque concluido en tiempos modernos, usa también la fábrica de ladrillo y es un claro ejemplo del arte mudéjar aragonés, pero guarda una construcción anterior hecha a base de sillares de piedra que se contempla todavía en la cabecera, en los contrafuertes escalonados de ésta, la fachada meridional, tres vanos en esa misma parte sur o la base del campanario (antes torre del homenaje del castillo).

Otra de las razones que nos podrían hacer pensar que se tratase de esta parroquia es el estilo que presenta el antiguo ábside (ahora coro). En palabras de José Luis Pano, en dicho lugar: «se despliega una decoración, escueta y sencilla, a base de escudos -ya desaparecidos- en las claves de sus bóvedas; ménsulas sin labra en las que apean nervaduras y, bajo algunas de estas ménsulas, baquetones que se frustran al poco de nacer y que poseen un marcado aire cisterciense» (Pano, 2002: 51). El estilo cisterciense es el rasgo definito- 


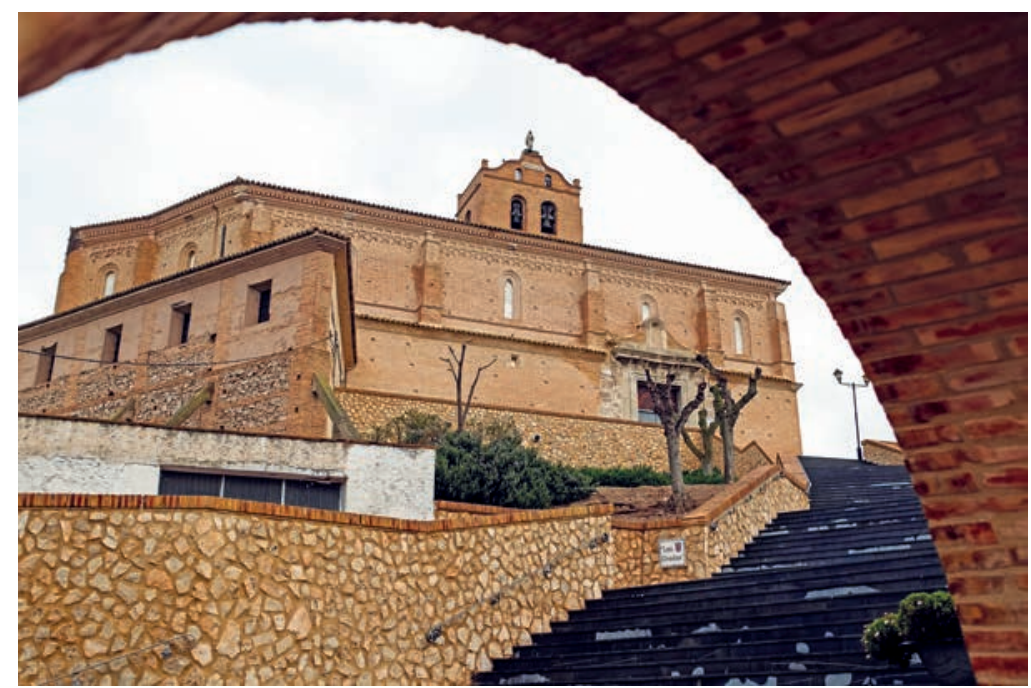

Fig. 3. Iglesia de San Lorenzo Mártir (Magallón). Fotografía de Teresa Salvador.

rio de los templos observantes, que a su vez buscan la sencillez y la austeridad en su fábrica como reflejo de su regla. La planta originaria de San Lorenzo era de nave única y ábside de cinco paños, cubiertos por bóveda de crucería simple, en ese sentido se asemeja a otras iglesias que siguen esa misma línea como por ejemplo la de Santa Ágata o la iglesia de Santa María de Pedralbes, ambas en Barcelona, y también a la iglesia del monasterio de la Santísima Trinidad de Valencia, fundado por la reina María, razones que nos hacen pensar en que la obra de Magallón se realizó al amparo de las corrientes estéticas observantes.

Otra de las intervenciones de María de Castilla tuvo lugar en el Hospital de Nuestra Señora de Gracia de Zaragoza. Es evidente que, como tantas otras reinas medievales, la preocupación por mostrar su caridad cristiana y ayudar a los más desfavorecidos constituyó uno de los cometidos asociados a su desempeño reginal. Los hospitales fueron uno de los puntales de las villas y ciudades en cuanto al amparo de sus ciudadanos, de pobres, viajeros e incluso de niños desfavorecidos y abandonados. Cumplieron, en este sentido, una labor social fundamental y, mismo tiempo, representaron los valores de la piedad y la bondad cristiana. 


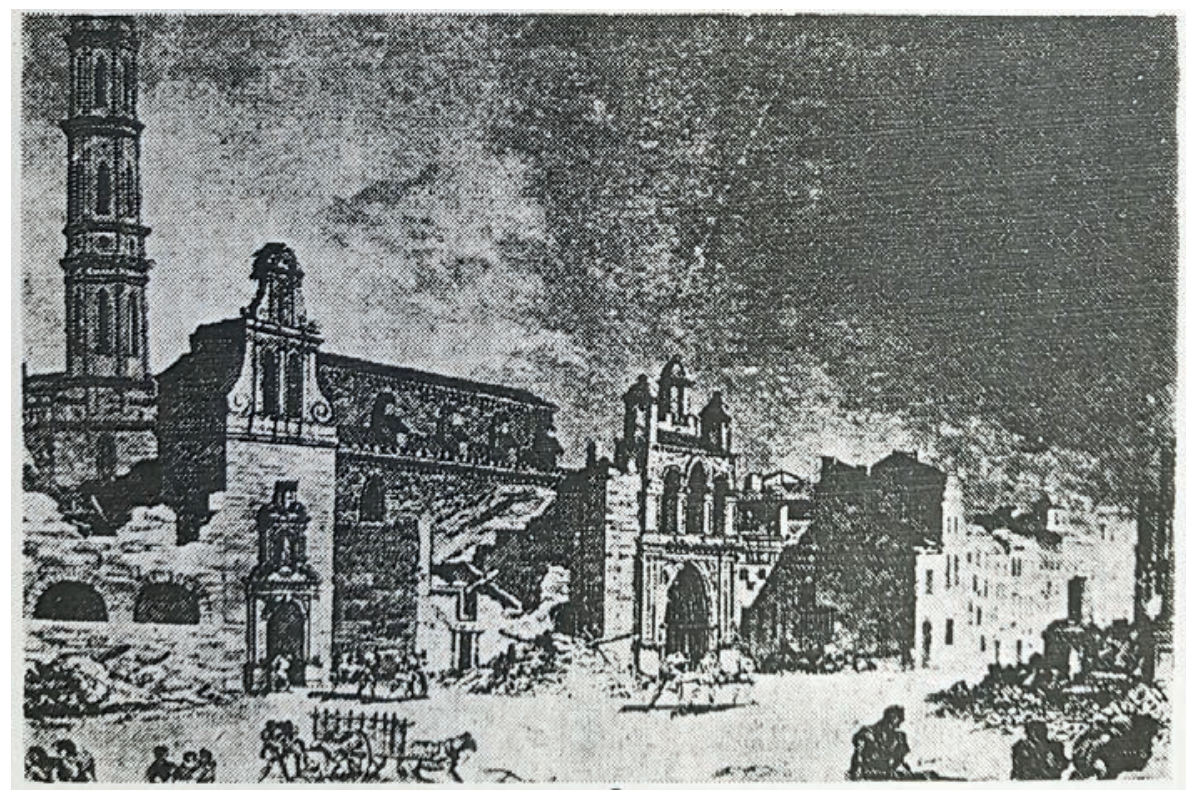

Fig. 4. Grabado del antiguo Hospital Real y General de Gracia, Zaragoza. Antes del sitio de la ciudad en 1808. Fuente: José Blasco ljazo (1948-1960), «¡Aquí. Zaragoza!» El Noticiero, Tomo VI, p. 355 .

Nuestra Señora de Gracia fue fundado en 1425 por los jurados de Zaragoza y dos representantes del Capítulo de la Seo. Este hospital, ubicado en el Coso, casi enfrente de la puerta Cinegia (Villagrasa, 2016: 54-117), fue conocido por el nombre de «Hospital de Gracia» y constituyó una de las instituciones asistenciales más modernas y complejas de la Corona. Acogió a enfermos, niños abandonados, mujeres embarazadas, «locos», mendigos, ancianos y también gente importante (García Herrero, 2012: 1371). Este centro hospitalario se erigió como esperada respuesta para un cúmulo de necesidades: aunque no fue el único hospital en la ciudad, los embates de la peste hicieron necesario la aparición de un nuevo centro para atender a enfermos. La mayor parte de las personas que se albergaron allí eran gente pobre, sin recursos, como en la mayoría de los hospitales medievales, de manera que estas instituciones desarrollaban más un servicio de caridad que sanitario. Por esa razón estuvieron dirigidos por religiosos (en muchos casos mendicantes), lo que hizo más atractivo para los monarcas el patrocinio hacia estas casas de caridad que tu- 
vieron un papel fundamental a la hora de enaltecer sus propias virtudes y hacer alarde de su linaje. No obstante, también hubo interés de patrocinio de este tipo de centros por parte de seglares y de cofradías (Falcón, 1980: 188-189).

Según las fuentes, la fundación de este centro hospitalario fue llevada a cabo por parte de la reina María y de su marido, el rey Alfonso el Magnánimo, a petición de la población, que demandaba disponer en la ciudad de Zaragoza de un complejo hospitalario general. El rey no tardó en aceptar la oferta y enseguida envió al fraile franciscano Francesc Berbegal para que lo comunicara a los jurados y el consejo de la ciudad (Falcón, 1980: 188-189). La fundación se materializó en 1438 a cargo del abad de Santa Fe (García Herrero, 2012: 1372). Pero, aunque ésta fuese una acción conjunta entre la reina y el rey, fue realmente la reina María quien estuvo apoyando y tutelando el referido hospital. Así, en una carta que la soberana escribió a Pere Queralt, fraile predicador de Lleida, expresaba su intención de hacer un estatuto u ordenamiento para que ningún enfermo se encontrase desatendido. Y, en otra carta, dirigida al consejero del rey, el arzobispo de Zaragoza Dalmau de Mur i Cervelló, pedía que estos enfermos fueran tratados solamente por médicos del propio hospital. ${ }^{20}$ Partiendo de estas solicitudes, podemos suponer que la reina fue quien realmente tuvo constancia y cuidado de lo que en este hospital sucedía y, por consiguiente, se encargó de las reformas pertinentes y de las necesidades de los enfermos. Es posible que la participación del rey fuese más institucional que efectiva.

\section{La elección de cargos en el seno de los monasterios y la resolución de conflictos}

Por otro lado, aparte de la promoción de monasterios o conventos, la vinculación de la reina con estas instituciones fue más allá que la simple financiación o la reforma arquitectónica. Entre los asuntos que la monarca también abordaba en estos centros, estuvieron los problemas de convivencia entre sus ocupantes, la elección de religiosos o de abadesas o el otorgamiento de rentas, entre otras muchas cosas. Uno de los centros en el que María de Castilla tuvo que intervenir fue el monasterio de Sijena, que se hallaba inmerso en diversas tensiones (Ubieto, 1998: 154-155). 
El monasterio de Sijena estaba muy unido a la nobleza aragonesa desde sus orígenes y supuso un lugar de paso y residencia frecuente. Por ello, no resulta extraño pensar que dicho cenobio estuviese al arbitrio de los gobernantes. La cuestión que debió resolver la reina estuvo relacionada con la elección de la nueva priora, Joana de Biure, nombrada directamente por la reina que, de este modo, desatendía a la otra candidata, Isabel de Prades, monja en este mismo monasterio:

La Reyna. Procuradors. Nos scrivim a nostre sant pare en Cort romana sobre lo priorat del Monestir de les monges de Sixena en província d'Aragó situat, del qual Monestir és prioressa la be amada nostra sor Johana de Biure, la qual aprés que fon morta la prioressa que darrerament lo possehia, fon feta per les monges del dit Monestir be e canònicament alguna de les dites monges no discrepant la dita sor Johana de Biure en prioresa del dit Monestir de Sixena per virtuts sues honestat e prudencia e per la gran augmentació que per lo seu bon regiment ha haut e rebent lo di o dit Monestir, segons som de açò plenament informada la qual elecció fon acceptada e confermada per lo sant pare Nicholau Quart de benaventurada recordació precessor de nostre Sant Pare, e a mes molts dies de la dita elecció feta sor Isabel de Prades monja del dit Monestir ha litigat e huy en dita litiga en Cort Romana contra la dita prioressa impugnant aquella e violent la quitar del dit priorat e volent ella esser prioressa del dit Monestir. E la qual dita sor Ysabel de Prades fon donat callament perdurable sobre lo dit priorat per lo dit sant pare papa Nicholau quart. En aprés la dita sor Johana de Biure prioresa ha possehit e posseeix fins al present lo dit priorat en pau e sens contradicció alguna... ${ }^{21}$

[...] monestir ne es estat reformat e reparat per tal declarats vos tota nostra voluntat moguda per los dits respectes e vehents que si lo dit nostre sent pare no dona callament e fi a la dita sor Ysabel de Prades e aquest litiga pus avant es e serà ofici de gran destrucció del dit monestir e turbació del divinal e al screure dec déu e encara serà sustentació de bandositats, scandols, boegues e remors entre los parents e amichs de les dites sor Johana de Biure e sor Ysabel de Prades les quals comprenen tot lo principat de Cathalunya. E nos volriem dar orde que no començassen noves bandositats en Cathalunya, car de les que y son e nos desplau ans volens per tot nostre sforç prevenir a la preparació de cabiscols que per aquest litigi de les dites dues monges se poran seguir sa callament no es donat a la dita sor Ysabel de Prades escrivim de present molt afectuosament al dit cardenal canonensis jutge de la dita causa. ${ }^{22}$

La capacidad coercitiva de la reina es evidente en este caso. El proceso para nombrar a Joana de Biure como candidata tuvo lugar al menos dos años 
antes de los acontecimientos, en 1455, cuando la reina envió una carta al obispo de Tarazona hablándole de las virtudes de esta mujer y diciendo que era «la más buena e sana parte de aquella [...] la venerable religiosa e amada nuestra, nuestro Santo Padre Nicolau Quinto, que Dios haya por sus provisiones apostólicas atorgó conformación por mayor autoridat [...] por sus virtudes e buena vida es possedido dicho priorato». ${ }^{23}$ La reina apelaba así a la buena vida y rectitud de esta monja, que había sido todo un ejemplo a seguir en la comunidad de Sijena, para ocupar el cargo de priora.

Por otro lado, María de Castilla también se preocupó por el estado de las religiosas del monasterio de Cambrón, en Huesca. Fundado por Pedro II con monjas cistercienses en 1203, (Martínez Buenaga, 1987: 185) fue símbolo contra el enemigo musulmán y tenía el objetivo de cristianizar ese territorio (Ubieto, 1999: 150). No obstante, más importante en este estudio que el monasterio de Cambrón propiamente fue el cenobio de Santa María de Forís (extramuros de Huesca), donde la misma comunidad de religiosas que habitaba Cambrón se estableció allí. Ignacio Martínez manifiesta desconocer las razones de dicho traslado documentado entre 1454 y 1473. En ese último año, las monjas volvieron a Cambrón y el convento de Forís fue ocupado por religiosos agustinos (Martínez Buenaga, 1985: 434). La Real Cancillería de la reina María confirma, por otra parte, que en 1456 estas monjas ya no estaban en Cambrón aludiendo a lo que podría ser una consecuencia de los desórdenes e incorrecciones de sus ocupantes. Ello se desprende de una carta que la reina recibió del abad de la Oliva después de su visita al monasterio:

Totes de vostra orde ates que lo abbat de la Oliva ab comissió expressa del abbat de Cistell volia e ha volgut vesitar lo dit monestir e monges olim de Cambron han contradit e contrastat ser vesitades per lo dit abbat ni per altres algu. Empero ab gran afany lo dit abbat ha pogut obtenir que les visitas $[\ldots]$ en la qual, segons havem entés, se han trobades prou coses dignes de correcció e smena segons pus larc en lo dit procés e informació lo qual lo dit abbat vos tramet veureu. ${ }^{24}$

La reina María hizo ir expresamente al abad del monasterio de la Oliva para reformar a estas monjas, que se oponían a ser vistadas por él. La reina pidió al religioso que «por servicio de dios bien e descargo de vuestra anima e de la de las dichas monjas vesiteys aquellas e del dicho monesterio en forma 
devida e tal si en aquel, nuestro señor dios sea servido e no offendido e de elles tornadas a devida obediencia puedan aconseguir aquelles fruyto que en las persones religiosas, buenas, honestas e obedientes observando la dicha religión servirán $[\ldots] \gg .^{25}$

Parece ser que la autoría de dicho traslado se debió a Damiata Flunián, que fue abadesa de Cambrón y que también aparecía documentada como abadesa de Santa María de Forís (Martínez Buenaga, 1985: 460). ¿Posiblemente se negaban estas monjas a seguir las normas de la Observancia y por eso marcharon a Forís? Estas reticencias a la nueva regla eran habituales, y hay otros testimonios que lo confirman: en el momento en que la reina María y el rey Alfonso fundaron el convento de Santa María de Jesús de Valencia, en 1428, dictaminaron que, tanto los nuevos religiosos observantes, que habían de ocupar dicho cenobio, como los franciscanos conventuales que ya poblaban otro anterior fundado en Valencia años atrás siguiesen la Observancia. Estos últimos se negaron a seguir la nueva regla, en consecuencia, el rey ordenó que se expulsara del convento a los que no fueran afines a la reforma. ${ }^{26}$

En otras ocasiones, las disputas entre los ocupantes de estas casas de religiosos y religiosas eran en parte el resultado de vivir en el propio convento hijas de familias nobles, frecuentemente con escasa vocación, ocasionando entonces problemas de convivencia. La mayor parte de las veces eran las monjas, o incluso la abadesa, las que los generaban por negarse a respetar las normas de clausura, entre otras cuestiones. Esto fue precisamente los que aconteció en el Monasterio de Pedralbes de Barcelona, donde la abadesa, sor Isabel de Montcada, fue depuesta de su cargo, en 1443, por negarse a cumplir la clausura (Soriano, 2006: 193). En ese caso, estaríamos enfrente de una posible resistencia a la conversión coletina que la reina pretendía aplicar como hacía con los conventos y monasterios masculinos. La reforma coletina era la versión femenina de la Observancia, y debía su nombre a Colette de Corbie (1381-1447), quien instituyó en la orden de las clarisas el rigor y la austeridad de la regla inicial (Castellano, 2005: 153).

Más espinoso resultó el asunto del monasterio de Veruela, donde la reina no vaciló tampoco a la hora de solucionar el problema que allí acuciaba. En vistas de la llegada del visitador del monasterio, los monjes que lo habitaban quisieron denunciar los abusos que cometía el abad. Esto fue una prueba de 
fuego para la reina quien, con la intención de evitar el escándalo, les exigió no decir nada mientras el visitador estuviese en Veruela:

La Reyna. Nos porque los abbades de Scala Dei e de Flarano del Reyno de Francia vienen al monesterio de Veruela por visitar e reformar aquel assó como son tenidos segund regla de llur orden, davemos puestos en nuestra salvaguarda e contención e guiados e assegurados en nuestra fe reyal los dichos abbades e XI monges del dito monesterio de Veruela, qui son idos a los ditos visitadores de lur orde por demandar justicia a ellos de los excesos por el abbat de Veruela en el dito monesterio comesos e perpetrados segund por otra letra nuestra parte veer poredes. Porque notificades vos la dita salvaguarda el dito nuestro guiatge e asseguramiento dezimos e mandamos expressamente e de cierta sta dins nuestra indignación que estado cuanto los ditos abbades staran en nuestro Regno por fazer la dita visitación e reformación vos ni otro por vos no vayades en el dito monesterio e reformación ni los perturbedes en lur exención ni actos por ellos fazederos. Certificantes vos que.n de sto nos faré desplaza e servicio, e del contrario desplaza e assin vos lo daremos a coneixer por obra dada en el monesterio de Pedra e los territorios de Barcinona. Dins nuestro siello secreto a XXVI de setiembre del anyo MCCCCXXII. La Reyna. ${ }^{27}$

En esta carta se puede ver la relación de Veruela con el monasterio francés de quien dependía, junto con el monasterio de Escaladieu (o Scala Dei). Los religiosos de la abadía de Flaran, fundada en 1151 en Gers, Occitania, (Martínez, 2008) llegaron a Veruela junto con los monjes provenientes de Escaladieu con la misión de reformar el monasterio. Veruela era uno de los principales monasterios de Aragón, y al igual que los de Piedra o Santa Fe, constituyó la cabeza de un importante señorío territorial que incorporaba toda una serie de villas y propiedades, y que además contaba con el favor regio (Cabanes, 1985; Rodríguez Lajusticia, 2017). Tanto Alfonso II como Jaime I lo dotaron de cuantiosas rentas (Ubieto, 1999: 138) aun cuando la orden, en origen, no podía percibir ningún tipo de diezmos o censos (Conde, 1983: 91). Tal vez, por ese augmento de bienes y poder, en manos de un abad derrochador, se llegó a tal situación.

Finalmente, los once monjes denunciaron la situación por la que pasaba el monasterio culpabilizando a su abad, Antonio de Sijena. En una carta, publicada por Rafael Conde, se habla de un memorial contra el abad presentado por once monjes de Veruela que denunciaban las irregularidades administrativas 
que tenían, al parecer, la misión de acrecentar por parte de aquel, las rentas y los bienes del monasterio. En dicho proceso se apelaba a la excomunión del abad generado por el abad de Poblet, fray Juan Martínez Mengucho, que era el visitador y reformador general de los monasterios cistercienses (Conde, 1983: 92). No creemos que la reina dejase impune al abad de Veruela, sabiendo como era de importante para ella la vuelta al rigorismo, la disciplina y la austeridad que caracterizaba a la Observancia. Aun así, los abades que se sucedieron en el cargo en Veruela tampoco fueron mejores que Antonio de Sijena, ya que, en 1456, el nuevo abad de la Veruela acabó accediendo también a las pretensiones del rey y del Papa y, finalmente, a las de la reina María, quien pidió a Miguel Delgado, consejero y lugarteniente del limosnero del rey en la abadía de Poblet, que buscara un nuevo responsable para el cargo a causa de la «perversa y disoluta» vida que llevaba en Veruela:

Mestre Delgado, por la perversa vida e dissoluta que lo abat del Monestir de Veruela pertana el religioso e amado consellero e limosnero del senyor lo abat de Poblet hi facia presó teniendo se del qual el dicho abat ha recorrido a nuestro Santo Padre e al senyor Rey e se dupda no halla fecho o fagare formación de su abadiado en el fijo de mossèn Joan Cerdan qui és en vuestra companya. E por cuanto aquel monasterio ha necesario reformación e persona anciana e que de vea vos rogamos muy estretamente que por servicio de Dios e contemplación nuestra pues lugartenéis e cuanto en vos sea de desorden e queraes trebaiar que si resignacón, permutación e pacto alguno se ha a facer del dicho abadiado se faga en persona dispuesta e tal que Dios ne sea seguido e el dicho monasterio como ha necesario redreçado e regido merito ne habéis e a nos qui solo en esto nos mueve, lo que esguarda servicio de Dios mucho nos complacéis. Data en la nuestra Ciudad de Borja a VIII dias de enero de MCCCCLVI. La Reina

$\mathrm{Al}$ religioso amado consellero exconsuero del senyor Rey mestre Miquel Delgado mestre en Santa teologia del monasterio de Poblet. ${ }^{28}$

La relajación de las órdenes en la baja Edad Media y el enriquecimiento de muchos abades arruinaron estos cenobios desde el punto de vista, no solo económico o arquitectónico, sino también de la moral. El deseo de obtener bienes y dinero alejó a los religiosos del objetivo del orden, y, por eso, la solución de la reina fue que se creara una comisión con el abad de Poblet a causa de «les solucions e mala vida de aquest de Veruela se pot e deu atorgar par de no res de temps ençà ha destroït quasi aquel monestir que era dels antichs d'Aragó: diminuint sempre les propietats e rendes lo que si molt ha de durar 
no cal sinó que lo dit Monestir serà del tot en terra en lo que.s necessari que per servey de Déu e decàrrech del dit nostre Sant Pare pus notificat li és e contemplació de la dita senyora hi sia provehit. $\rangle^{29}$

El caso del abad de Veruela no fue un hecho aislado. Otro de los monasterios que ensombrecían a la orden del Císter fue el de Santa Fe de Zaragoza. Fundado por Miguel Pérez Zapata y su esposa, Sancha Garcés de Januas en 1341, fue un cenobio surgido a partir del Monasterio de Fontclara, en Albalate del Cinca, en Huesca (Giménez Ferreruela, 2004-2005: 109). Desde el siglo XIV este monasterio fue favorecido por la monarquía: el rey Pedro el Ceremonioso le concedió la exención de diversos impuestos y cargas reales. En 1429, el rey Alfonso el Magnánimo les otorgó franqueza de peaje por todo el reino (Ruíz de Tremiño, 2013a: 19) y la reina María también les concedió una serie de privilegios como por ejemplo poder llevar pan y vino, entre otras mercancías, por Zaragoza y su término libremente (en 1439), la concesión, en 1442, de la jurisdicción civil y criminal alta y baja de los lugares de Cadrete y Cuarte, así como dar protección y salvaguarda real al monasterio y a sus vasallos, entre otros (Giménez Ferreruela, 2012: 20). Pero, aparte de todas estas intervenciones reales, que quedan reflejadas en los documentos administrativos del monasterio, había otros asuntos que acuciaban también a los reyes, y que solo suelen explicitarse en una correspondencia más privada como en este caso nos ofrece, de nuevo, la Real Cancillería de la reina María, donde se habla de un religioso llamado Bernat Cardona, que aparecía descrito como una persona de «mala vida». ${ }^{30}$

Cuando María de Castilla acudió al monasterio, en una de sus visitas, el resultado no fue muy esperanzador. Aquel lugar estaba en «tanta dissolució e mal exemple vers lo dit abat» que la situación no podía seguir así. ${ }^{31}$ Los problemas surgieron como consecuencia de ciertos desacuerdos entre el abad fray Bernat Cardona y fray Candela. Este último se había criado desde pequeño en el monasterio, pero parece ser que había llevado una vida deshonesta, hecho que causó ciertas desavenencias con fray Cardona. El conflicto llegó a los oídos del prior de Poblet, a quien la reina puso en aviso por no haber solucionado los problemas que concurrían en Santa Fe. El abad de Poblet, con tal de castigar la actitud del religioso, lo apresó en Poblet. La reina defendió la acti- 
tud adoptada por el abad de Poblet y que dicho fraile recibiese el castigo oportuno por tales conductas, aceptando la elección de un nuevo abad aprobado por el Papa. ${ }^{32}$ Seguramente el cambio de abad se hizo efectivo al año siguiente, pues según la relación de abades que publicó Héctor Giménez, Bernat Cardona se documentó en el cargo entre 1453 y 1456. Así mismo, el tal fray Candela concuerda, según dicha relación de abades, con un religioso llamado Juan Candela que fue prior y después abad, justo antes que Bernat Cardona, concretamente entre 1443 y 1453 (Giménez Ferreruela, 2004-2005: 136). Viendo que ambos llegaron a ser abades, es muy posible que tales disputas tuvieron precisamente esa razón de ser: alcanzar ese mismo rango.

Por último, cabe señalar que algo similar ocurrió en el monasterio de Piedra, donde la reina quiso poner fin a los abusos y malas prácticas que se habían dado en los últimos años. Por esa razón, la monarca envió una carta a los jurados del lugar, ya que «nos desplaze muy mucho por cuanto nos lo havemos en singular reputación el dicho monasterio e ciertamente si assin vos rogamos e encargamos effectuosamente que por servicio de dios e contemplación nuestra de aquí adelante hi querades guardar e haver los dichos Abbat, monasterio e coses d'aquell por bien e favorablemente por recomendacio». ${ }^{33}$

\section{Conclusiones}

En conclusión, debemos destacar que la reina María de Castilla tuvo un papel fundamental en su época como promotora o benefactora de monasterios y conventos, pero también de hospitales e iglesias. Ello nos ofrece una visión ampliada de la información conocida hasta ahora, y que se reducía a la erección de unos pocos conventos como el de Santa María de Jesús de Valencia, o el convento de la Trinidad, y de otros cenobios u hospitales en los distintos territorios peninsulares. Desde el ámbito aragonés y zaragozano en particular, María de Castilla desempeñó un papel muy importante en la difusión de la reforma Observante. Y, dentro de esa búsqueda de disciplina y de rigorismo de la regla que tanto caracterizó a la monarca, se enmarcaron todas sus acciones, bien fuera en el control de los religiosos en antiguos monasterios, la elección de abadesas afines o la fundación y reforma de antiguos conventos en otros nuevos dedicados al sagrado nombre de Santa María de Jesús. Estos aspectos, 
concretados aquí en el caso de Aragón, se proyectaron tanto para el reino de Valencia como para Catalunya, estableciendo una red observante, si se me permite la expresión, de cenobios afines. El mecenazgo hacia los conventos observantes, sobre todo franciscanos, fue lo que más presente estuvo en su programa de reformas. La reina María de Castilla hizo suyas estas intervenciones, siempre aconsejada por el franciscano observante Mateo de Agrigento, para imponer este modelo espiritual elegido por la monarquía y por ella en particular.

La reina María fue una soberana implicada en la construcción de nuevos edificios, en la reforma de muchos otros -siguiendo el esquema cisterciense-, pero también puso su empeño en la búsqueda del orden y la disciplina en los ámbitos monacales que habían descuidado el seguimiento de la Regla. Por ese motivo, su actitud negociadora en busca de la resolución de los conflictos, así como su habilidad política para elegir a los ocupantes de monasterios o conventos, queda puesta en relieve en este estudio. Se refuerza así el valor de las palabras que escribió sobre ella el historiador Giménez Soler a afirmar que «la reina de Aragón fue superior a todos sus contemporáneos en talento, en virtudes y en energía; ella tuvo el valor y entereza que faltaron a su hermano, fue la única que comprendió a su marido y su más fiel e inteligente servidor; ganaba en nobleza y buenos propósitos a su cuñado Juan; en prudencia, a don Enrique, y en todo a todos los demás». ${ }^{34}$

\section{Referencias bibliográficas}

CABAnes Pecourt, María de los Desamparados (1985), El libro de registro de Veruela. Zaragoza, Textos de Historia Moderna 2. Edición Facsímil Vía de la Hispanidad, s.n.

CAstellano i Tressera, Anna (2005), «Los franciscanos del «conventet» de Pedralbes (Barcelona).» En Gonzalo Jiménez Fernández-Gallardo (ed.), Los franciscanos conventuales en España, II Congreso Internacional sobre el Franciscanismo. Barcelona, Asociación Hispánica de Estudios Franciscanos: 149-158.

Conde Delgado DE Molina, Rafael (1983), «La situación económica del Monasterio de Veruela a principios del siglo XV», Cuadernos de historia de Jerónimo Zurita, 45-46: 91-114.

EARENFIGHT, Theresa (2010), The King's other body: Maria of Castile and the Crown of Aragon, Philadelphia, University of Pennsylvania Press.

34 Andrés Giménez Soler (1902), «Retrato histórico de la reina Da María», Butlletí de la Reial Acadèmia de Bones Lletres, Barcelona: 82: 71-81. 
FALCÓN PÉREZ, María Isabel (1980), «Sanidad y Beneficencia en Zaragoza en el siglo XV», Aragón en la Edad Media, 3: 183-226.

FALCÓN PÉREZ, María Isabel (2011), Zaragoza en el siglo XV, morfología urbana, huertas y término municipal, Zaragoza, Institución Fernando el Católico.

GArcía Herrero, María del Carmen (2012), «Aragón y el Monasterio de la Trinidad de Valencia: la renuncia a financiar el proyecto de la reina María.» En Mundos medievales: espacios, sociedades y poder: homenaje al profesor José Ángel García de Cortázar y Aguirre. Santander, Universidad de Cantabria: 1365-1378.

García Herrero, María del Carmen (2013-2014), «De belleza y piedad. Promociones de María de Castilla, reina de Aragón (1416-1458)», Lambard. Estudis d'Art medieval, 25: 37-62.

GARCÍA Herrero, María del Carmen (2017), «Reginalidad y fundaciones monásticas en las Coronas de Castilla y Aragón», Edad Media. Revista de Historia, 18: 16-48.

García Herrero, María del Carmen y MuÑoz Fernández, Ángela (2017), «Reginalidad y fundaciones monásticas en las Coronas de Castilla y Aragón», Edad Media. Revista de Historia, 18:16-48.

GARCÍA MARSILlA, Juan Vicente (2007), «La demanda y el gusto artístico con la Valencia de los siglos XIV al XVI.» En Ximo Company, Vicente Pons, Joan Aliaga (eds.), Libro de estudios. Exposició La Llum de les Imatges, Lux Mundi. València, Generalitat Valenciana: 375-407.

GIMÉNEZ FERRERUELA, Héctor (2004-2005), «El Real Monasterio Cisterciense de Santa María de Santa Fe (Zaragoza) en la Edad Media (1341-1610)», Aragonia Sacra: Revista de Investigación, 18: 101-136.

GimÉnEZ FERRERUELA, Héctor (2012), El registro General del Archivo del Real Monasterio de Santa Fe (Zaragoza). Zaragoza, Institución Fernando el Católico.

GIMÉNEZ SOLER, Andrés (1902), «Retrato histórico de la reina D. ${ }^{a}$ María», Butlletí de la Reial Acadèmia de Bones Lletres ,Barcelona, 1: 71-81.

GrAÑA CID, María del Mar (2017), «Catalina de Lancaster, la Orden de Predicadores y la reginalidad: las políticas conventuales», Edad Media. Revista de Historia, 18: 75-100.

GRAÑA CID, María del Mar (2018), «Mariología, reginalidad y poder en Isabel de Villena: una teoría política femenina del siglo XV», Mirabilia: Revista Electrônica de História Antiga e Medieval, 22: 96-127.

HEBRERA Y ESMIR (OFM) José Antonio (1705), Chronica seráfica de la santa provincia de Aragón de la Regular Observancia de nuestro padre San Francisco, Vol. II, Zaragoza, Diego de Larube impresor.

Hernández-León de SÁnchez, Francisca (1959), Doña María de Castilla, esposa de Alfonso V El Magnánimo. València, Universitat de València.

LOP OTín, Pilar (2010), «El convento de Nuestra Señora de Jesús de Zaragoza: presentación de un plano inédito del 1880», Artigrama, 25: 491-506. 
MANCINELli, Chiara (2017), «La Observancia franciscana en la provincia de Aragón (1380 ca.-1517): Aproximación a su estudio», Archivo Ibero-Americano, 77/284: 53-67.

Martínez Buenaga, Ignacio (1985), «El monasterio de Cambrón», Cisterium, 169: 407-500.

MARTínez BuenaGA, Ignacio (1987), «El Monasterio Cisterciense femenino de Cambrón.» En El Cister. Órdenes religiosas zaragozanas. Zaragoza, Institución Fernando el Católico: 183-198.

Murillo, fray Diego (1616), Fundación Milagrosa de la capilla Angélica y Apostólica de la Madre de Dios del Pilar y excelencias de la Imperial ciudad de Çaragoça, Barcelona, Sebastián Mateuad.

NARBOna CÁrCEles, María (2013), «De casa de la senyora Reyna. L’entourage de Marie de Castille, épouse d'Alphonse le Magnanime (1416-1458).» En Alexandra Beauchamp, Les entourages princiers à la fin du Moyen Âge. Une approche quantitative. Madrid, Casa de Velázquez: 151-167.

NARBOnA CÁRCELES, María (2014-2015), «El contenido devocional de las divisas: el azafrán y la olla ardiente de la Reina de Aragón (1416-1458)», Emblemata: Revista aragonesa de emblemática, 20-21: 435-452.

Pano Gracia, José Luís, Hernando Sebastián, Pedro Luís y Sancho Bas, José Carlos (2002), Magallón. Patrimonio artístico religioso. Borja (Zaragoza), Centro de Estudios Borjanos.

Pelaz Flores, Diana (2018), «Devoción y poder en la Corona de castilla a través del patronazgo de la reina María de Aragón (1420-1445)», Hispania Sacra, 142:407421.

RIERA I MELIS, Antoni (2011), «Catàstrofe, pànic i ritualitat a la baixa Edat Mitjana. La resposta de la societat catalana als terratrèmols de 1427-1428», Afers, 69: 375408.

RodríGuez LaJUsticia, Francisco Saulo (2017), «Documentos del siglo XIV del Monasterio de Santa María de Veruela no recogidos en su colección diplomática», Turiaso, 23: 161-194.

Rotolo, Filippo (GFM) (2006), Il beato Matteo d'Agrigento e la prinvincia Francescana di Sicilia nella prima metà del sec. XV. Palermo, Biblioteca Francescana, Officina di Studi Medievali.

RUBIÓ I BALAGUER, Jordi (1964), La cultura catalana del Renaixement a la decadència. Barcelona, Ed. 62.

RuBió I BAlagueR, Jordi (1990), «El beat frare Mateu d'Agrigento a Catalunya i València: notes sobre la vida religiosa en una cort del Renaixement.» En Jordi Rubió i Balaguer, Humanisme i Renaixement. Barcelona, Publicacions de l'Abadia de Montserrat.

RuíZ DE TREMIÑo ÍÑIGO, Santiago (2013a), «Fundaciones cistercienses y monarquía aragonesa: el Monasterio de Santa María de Santa Fe.» En Víctor Mínguez (ed.), 
Las Artes y la Arquitectura del Poder. Castelló de la Plana, Universitat Jaume I: 1263-1282.

Ruíz DE TREMIÑo ÍÑIGO, Santiago (2013b), «Fuentes documentales del Monasterio Cisterciense de Santa María de Santa Fe (Cadrete, Zaragoza)», Anales de Historia del Arte, 23: 187-199.

SILLERAS-FERNÁNDEZ, Núria (2003), «La piedad urbana de María de Luna, Reina de la Corona de Aragón (1396-1406).» En Salvador Claramunt Rodríguez (coord.), El món urbà a la Corona d'Aragó del 1137 als decrets de Nova Planta. XVII Congrés d'Història de la Corona d'Aragó. Barcelona, Universitat de Barcelona. Vol. II: 889-894.

Silleras-FERnÁndeZ, Núria (2008), Powery, piety and patronage in Late Medieval Queenship: María de Luna. United Estates of America, Palgrave Macmillan.

Soriano Triguero, Carmen (2006), «La reforma de las clarisas en la Corona de Aragón (ss. XV-XVI)», Revista de Historia Moderna, 3: 185-198.

Toledo Girau, José (1961), Inventarios del Palacio Real de Valencia a la muerte de doña María, esposa de Alfonso el Magnánimo. Valencia, Anales del Centro de Cultura Valenciana.

UBIETo ARTETA, Agustín (1998), Los monasterios de Aragón: función histórica, Zaragoza, Caja de Ahorros de Aragón.

Ubieto ArtetA, Agustín (1999), Los monasterios medievales de Aragón, Fundación Histórica, Zaragoza, Caja de Ahorros de la Inmaculada de Aragón.

VICENS SOLER, Maria Teresa (2009), «Aproximació al món artístic de la reina Maria de Castella.» En Maria Rosa Terés Tomàs (coord.), Capitula facta et firmata, inquietuds artístiques en el Quatre-cents. Barcelona, Cossetània: 193-262.

VIDAL FRANQUET, Jacobo (2014), «La cámara real de María de Castilla. Sus joyas y otras delicias suntuarias», Anales de Historia del Arte, 24: 593-610.

Villagrasa ElíAs, Raúl (2016), La red de hospitales en el Aragón medieval (ss. XII$X V)$. Zaragoza, Institución Fernando El Católico, Diputación de Zaragoza.

Villanueva Morte, Concepción y VillagrasA-Elías, Raúl (2013), «El hospital Sancti Spiritus de Borja y su contabilidad a principios del siglo XVI.» En Concepción Villanueva Morte, Antoni Conejo da Pena y Raúl Villagrasa-Elías (eds.), Redes hospitalarias: historia, economía y sociología de la sanidad. Zaragoza, Institución Fernando el católico: 149-160. 